

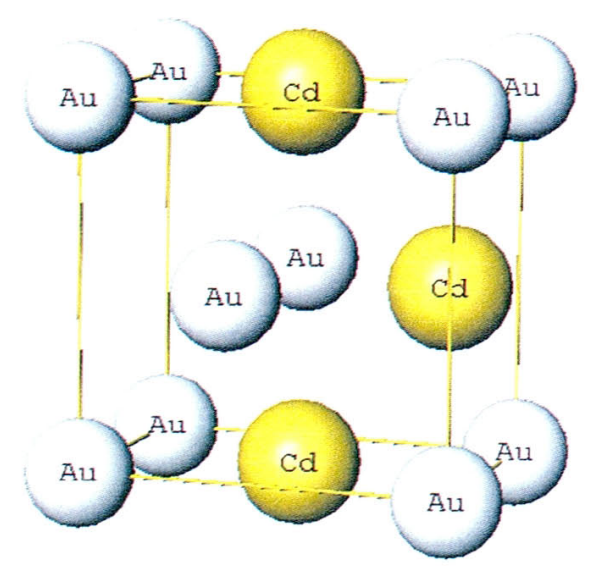

(a)

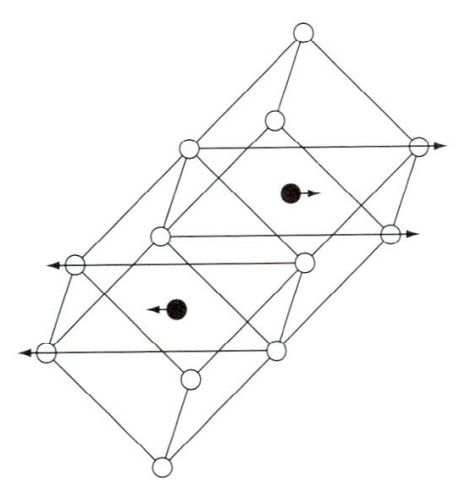

(b)

図 1 (a) $\gamma_{2}^{\prime}$ 相の結晶構造, (b) $\gamma_{2}^{\prime}$ 相へ変態するのに必 要な $(110)[\overline{1} 10]$ の動き.

表 $1 \mathrm{AuCd}$ 合金の母相と $\gamma_{2}^{\prime}$ 相, $\zeta_{2}^{\prime}$ 相の空間群, 格子 定数.

\begin{tabular}{cccc}
\hline \hline & 母相 & $\gamma_{2}^{\prime}$ 相 & $\zeta_{2}^{\prime}$ 相 \\
\hline 空 間 群 & $P m \overline{3} m$ & $P m m a$ & $P 3$ \\
\hline 格子定数 & $a=0.332 \mathrm{~nm}$ & $\begin{array}{l}a=0.4859 \mathrm{~nm} \\
\end{array}$ & \\
& & $\begin{array}{l}b=0.3151 \mathrm{~nm} \\
c=0.4766 \mathrm{~nm}\end{array}$ & $c=0.8095 \mathrm{~nm}$ \\
& & \\
\hline
\end{tabular}

ばれる図 $1(\mathrm{a})$ のような構造を持つ. B2 型の母相が B19 型 の結晶構造になるには, 図 1(b)に示すように様に(110)面で 交互に $[\overline{1} 10]$ へ変位させる事により，B19 型の構造を持つマ ルテンサイト相ができる(12)．もちろん一次の変態であるの で格子定数のとびがある. 母相と $\gamma_{2}^{\prime}$ 相の格子定数, 空間群 を表 1 に示す.

もう一つのマルテンサイト相は $\mathrm{Au}-50 \mathrm{at} \% \mathrm{Cd}$ 付近に現れ， ら’マルテンサイト相と呼ばれている。この結晶の構造を図 2(a)に示す ${ }^{(13)}$. 母相の<111>がマルテンサイト相の $c$ 軸にな る。格子定数と空間群を表 1 に示す。困 2 (a) を見ると非常 に複雑な構造に見えるが，この結晶構造の特徵的なところは， 1 本の 3 回軸上にのっている原子が, 三方晶の $c$ 軸 (3 回軸) の方向へ変位することである。一見複雑に見えるこの結晶構

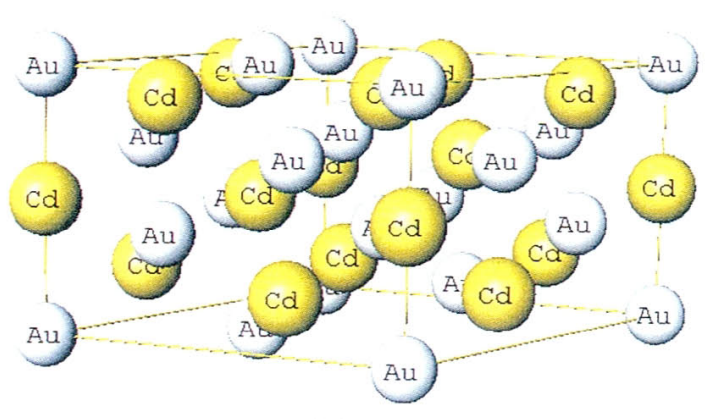

(a)
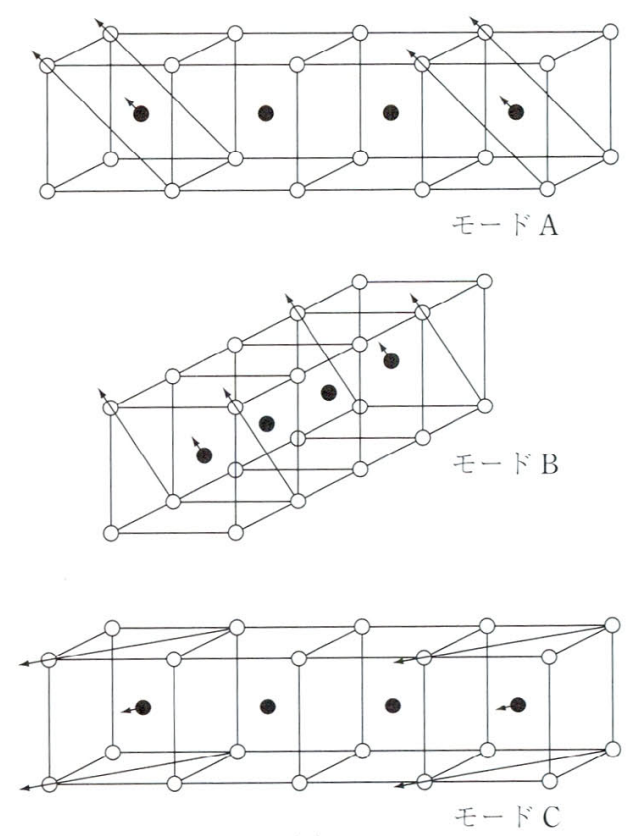

(b)

図 2 (a) $\zeta_{2}^{\prime}$ 相の結晶構造, (b) $\zeta_{2}^{\prime}$ 相へ変態する 3 つの $\{110\}<\overline{1} 10>$ モード.

造も， $\gamma_{2}^{\prime}$ 相同様に(110)面の原子変位によって表すことがで きる. 図 $2(\mathrm{~b})$ に $\mathrm{B} 2$ 構造の単位胞を 4 つ並べているが, こ の中の (110) 面が 3 枚拈きに[110]に变位するような原子の 動きを考える(Mode A).さらに，これと等価な 2 つ原子 の動き，(101)面の[101]，（011)面の[011]を考える (Mode B, Mode C).これらの原子の動きを合成すると[111]方向の 変位を持つ原子が生じ, 立方晶の〈111〉, つまり三方晶の $c$ 軸方向に動く原子を再現でき， $\zeta_{2}^{\prime}$ 相を作ることができる.

工業的に利用されている TiNi 系合金も, AuCd 合金で示 したような変態の様子を示す。つまり母相は B2 構造で, $\mathrm{Ni}$ の代わりに Fe をわずかに添加すると $\mathrm{R}$ 相といわれる $\mathrm{AuCd}$ の $\zeta_{2}^{\prime}$ 相と同様な結晶構造を持つ(14)ものに变態する。なた, $\mathrm{Cu}$ を添加するとB19 型の構造へ変態する ${ }^{(15)}$. さらに TiNi 系合金の場合には単斜晶 (monoclinic)のマルテンサイト相へ 直接変態するというパスもある. B2 から出発してこれまで 述べた $\mathrm{AuCd}$ 合金と同様な三方晶, 斜方晶の結晶構造をと るマルテンサイト相へと変態する様子を示したものを図 3 に 示す。 


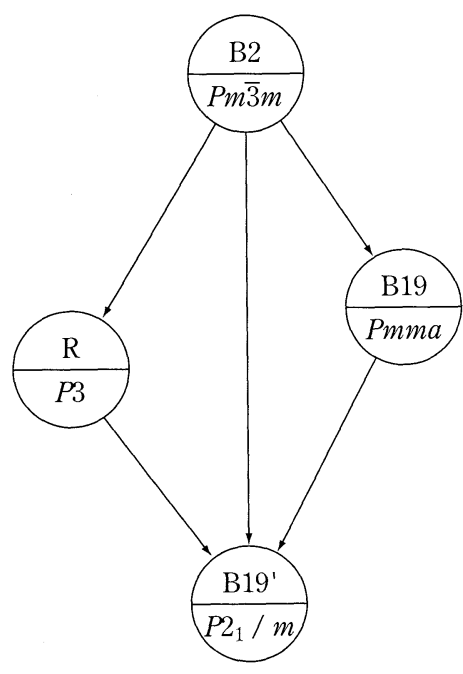

図 3 B2 母相からいろいろなマルテンサイト相へのパ スとその空間群.

なお， $\mathrm{R}$ 相は従来立方晶のく $111>$ 方向へ歪むことにより菱 面体晶 (rhombohedral)になると考えられ， R 相と名づけら れ説明されていたが，構造解析の結果からはこの解釈は適当 でない，また，菱面体晶 (rhombohedral) と三方晶 (trigonal) はともに 3 回の回転対称を持つことで特徴付けられるが, 菱面体晶 (rhombohedral) は三方晶 (trigonal)にセンターリン グをしてできた格子であるので，まったく同一ではないこと を付記しておく。

\section{3. 中性子非弾性散乱実験の結果}

前節での母相の結晶構造, およびマルテンサイト相の結晶 構造へ到る説明を考えると, マルテンサイト変態は単純その もので, フォノンのソフト化によって変態が起こる理想的な 系のように思える．前節で説明した原子の変位は $[\zeta \zeta 0] \mathrm{TA}_{2}$ フォノンのモードに対応する. 実際フォノンのソフト化が起 こっているかどうかは中性子の非弾性散乱が唯一といってい い実験手段である。しかしながら， AuCd 合金の場合には Cdが中性子の吸収剤として利用され，通常，実験をするの は不可能である. しかし同位体 ${ }^{114} \mathrm{Cd}$ を用いることによって 大幅に吸収を減らすことができ，実験を行うことができ た(16)(17).

まず， 光相を作る Au-49.5 at\%Cdについてみてみよう.

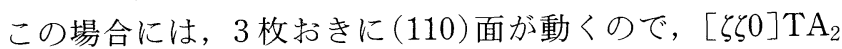
モードの $=1 / 3$ のフォノンがソフト化することに対応す る. 図 4 に $[\zeta \zeta 0] \mathrm{TA}_{2}$ のフォノン分散関係を示す ${ }^{(18)}$. マルテ ンサイト変態開始温度 $\left(M_{\mathrm{s}}\right)$ は $304 \mathrm{~K}$ であり, $M_{\mathrm{s}}$ へ近づく にしたがって なっている様子がわかる. $=1 / 3$ からわずかにずれている のも注目すべき点である．また， $M_{\mathrm{s}}$ よりも十分高い $425 \mathrm{~K}$ でもすでに幾分かソフトになっている様子もうかがえる，さ らにこの系の場合には，フォノンのエネルギーが全領域にわ

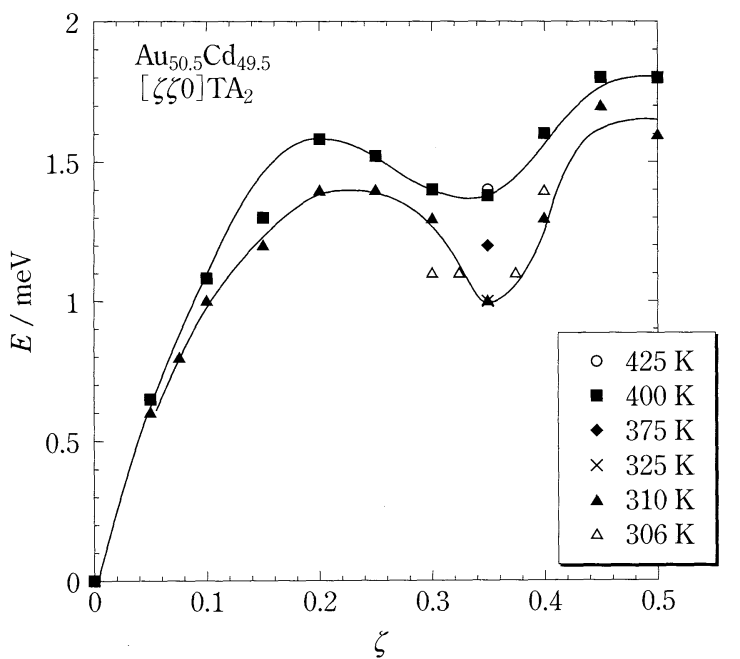

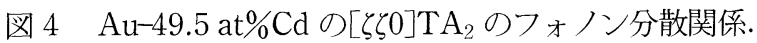

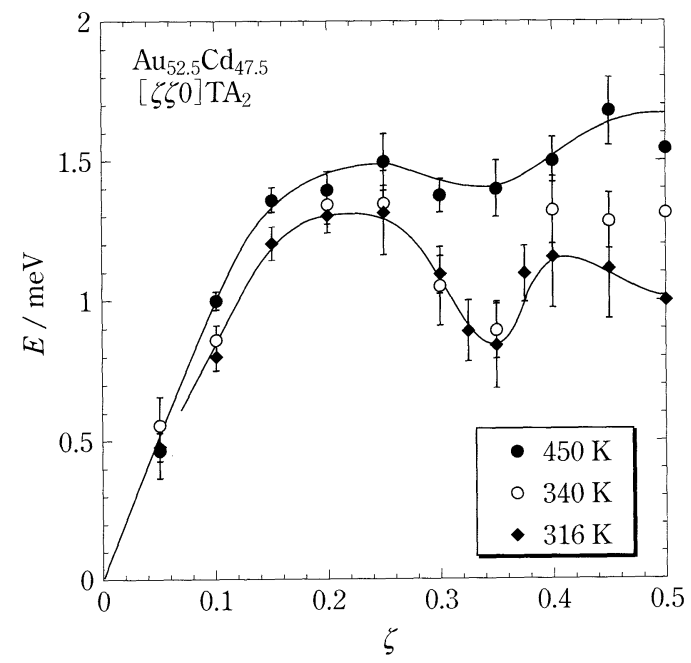

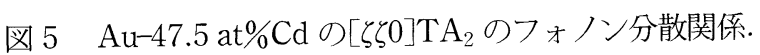

たって $2 \mathrm{meV}$ 以下であり, 著しく低いという点も注目すべ きである.

次に Au-47.5 at\%Cdについてみてみよう。この場合には

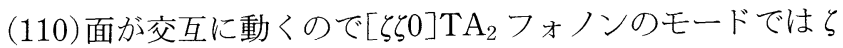
$=1 / 2$, つまり Brillouin zoneの境界でフォノンのソフト化

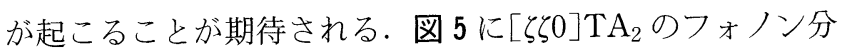
散関係を示す ${ }^{(16)}$. マルテンサイト変態開始温度 $M_{\mathrm{s}}$ は 312 Kである. まず Brillouin zone 境界に着目すると, 変態点に 近づくにしたがって確かにフォノンのエネルギーは低くな

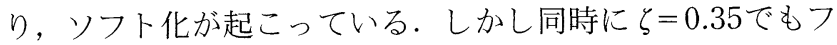
オノンのエネルギーの低下が起こっている.この系でもら= 1/3 からわずかにずれたところでフォノンのソフト化が見ら れている. フォノンの測定結果は, $\zeta=1 / 3$ 付近も $\zeta=1 / 2$ も どちらのモードもソフト化が起こっている.つまり, 二つの モードが競合していると考えることができる.

TiNi 系についても中性子の非弾性散乱の実験が行われて いる．Feを添加した TiNi $(\mathrm{Fe})$ では R 相といわれる結晶構 
造がマルテンサイト相として現れるが， $\mathrm{R}$ 相の結晶構造が明 らかにされる以前から， $\zeta=1 / 3$ 付近のフォノンのソフト化 が文献 (18) (19)（20）などに報告されている。 また，最近 $\operatorname{TiNi}(\mathrm{Cu})$ での中性子非弾性散乱の実験結果が報告され(21), $\zeta=1 / 2$ の顕著なソフト化が報告されている.

\section{Landau 流の現象論的な取り扱い}

マルテンサイト相の結晶構造，母相の結晶構造から，厳密 に対称性を考慮に入れた Landau流の相変態の現象論的な取 り扱いも行われている(22). $\gamma_{2}^{\prime}$ 相の場合はフォノンのソフト 化が逆格子空間の対称性の高い点で起こるが，(110)の面間 隔の 3 倍周期を考えなければならない $\zeta_{2}^{\prime}$ 相の場合は, Stokes and Hatch ${ }^{(23)}$ による逆格子点の対称性の考慮が必要 である. と=1/3 からのずれは考慮に入っていないが，現象 論的には母相とマルテンサイト相の結晶構造から類推した (110)面が交互に動くことによってできる $\gamma_{2}^{\prime}$ 相，3枚おきに 3 つのモードが組み合わされてできる $\zeta_{2}^{\prime}$ 相という描像によ って, 変態機構はうまく説明できる. フォノンのソフト化を 考え原子変位を計算すると, 構造解析で求まったマルテンサ イト相の原子位置をよく再現している ${ }^{(22)}$.

\section{5. 弾性散乱実験の結果}

中性子非弾性散乱実験は，格子系のダイナミカルな側面を 見るのに最適な実験手段である．静的な側面からのアプロー チもマルテンサイト変態を調べるためには重要な情報をもた らす：二つの異なったマルテンサイト相を得る組成の $\mathrm{AuCd}$ 合金に対してもX 線，中性子を用いた弾性散乱実験が行わ れている.

$\zeta_{2}^{\prime}$ マルテンサイトについて考えてみる. マルテンサイト

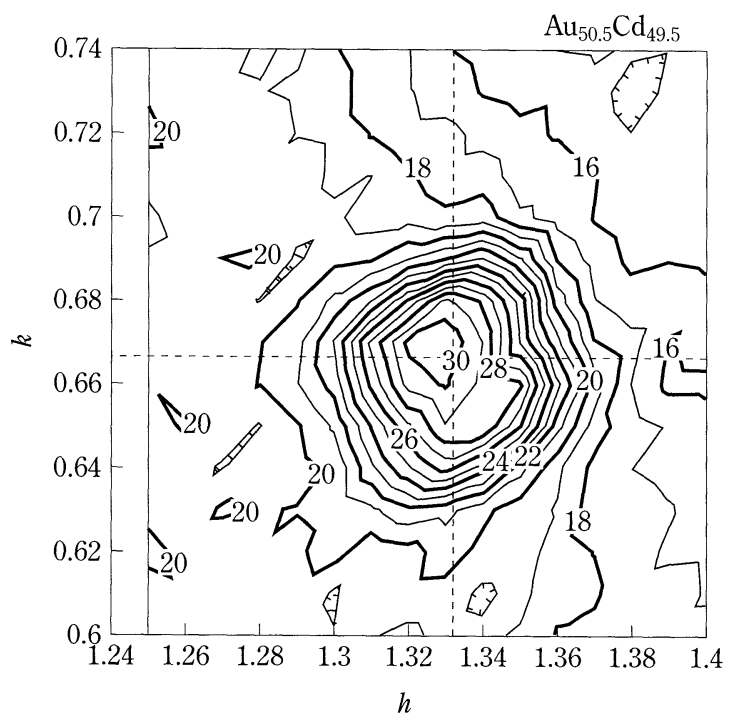

図 $6 \mathrm{Au}-49.5$ at\% Cd の母相の $[1-\zeta, 1+\zeta, 0]$ の $=$ $1 / 3$ 付近の散漫散乱.
相と母相の結晶の対応を考えると, [110]の 1/3の位置, た とえば $[1-\zeta, 1+\zeta, 0]$ の=1/3 や $2 / 3$ に新たに $\zeta_{2}^{\prime}$ 相の反射

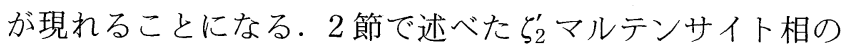
原子位置から推測される変態のメカニズムから考察しても, (110)の面間隔の 3 倍周期を考えるので同様である. Au49.5 at $\% \mathrm{Cd}$ の場合の $[1-\zeta, 1+\zeta, 0]$ $\zeta=1 / 3$ の位置につい て測定を図 6 に示す ${ }^{(24)}$. ごく弱い散漫散乱が現れている. マルテンサイトになると図 7 に示すようにバリアントに対応 して分裂し，その強度もマルテンサイトの Bragg 反射にな るので格段に強いものとなる，このことから，観察されてい る散漫散乱が徐々に成長してマルテンサイト相の反射になる わけではないと考えられる，つまり，前駆的にマルテンサイ 卜相の小さなものができているわけではないといえる.

$\gamma_{2}^{\prime}$ 相になる $\mathrm{Au}-47.5$ at\%Cdの場合を考えて見ると， [1$\zeta, 1+\zeta, 0]$ 1/2 の位置に散漫散乱が現れ, それが成長する

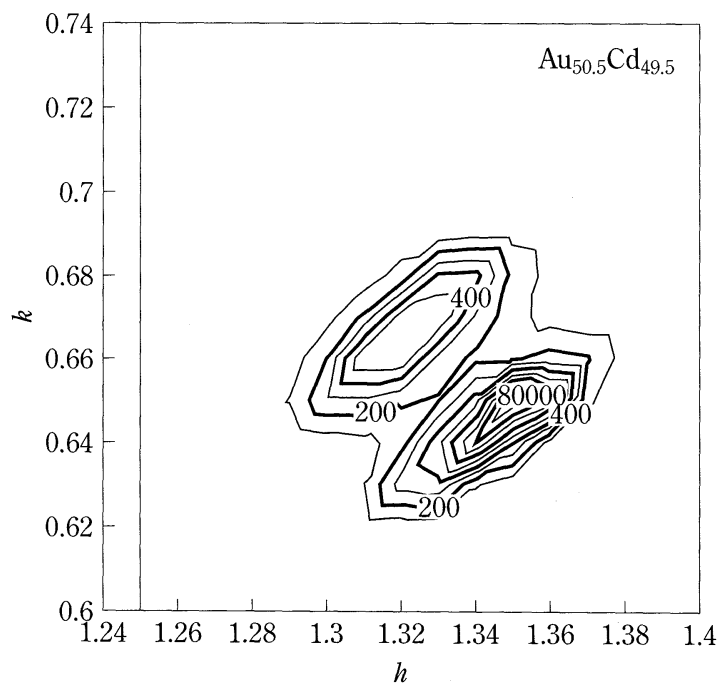

図 7 マルテンサイト変態を起こし, 図 6 の領域にマ ルテンサイト相からの反射が現れた。

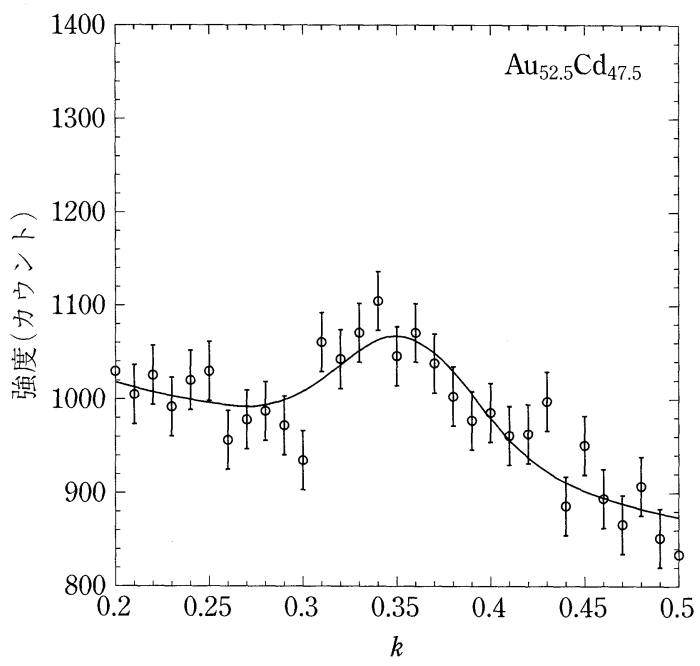

図 $8 \mathrm{Au}-47.5$ at $\% \mathrm{Cd}$ の相の $[1-\zeta, 1+\zeta, 0]$ の散漫 散乱. 
とマルテンサイト相になるというストーリーが描けるが，実 際に測定すると図 8 に示すように，やはり $1 / 3$ の位置付近 に散漫散乱が現れる ${ }^{(25)}$. この図の $1 / 2$ のころに着目して みると散漫散乱は現れていない。

この組成では, 弾性散乱で観察される[110]の $1 / 3$ 付近に 現れる散漫散乱には，時間依存性などのさらにおもしろい現 象も観察されているが(16)(25)，ここでは特に言及しない。時 間依存性についてはべイナイト変態であるという報告もなさ れている(26).

散漫散乱についてまとめて見ると, AuCd 合金では異なっ たマルテンサイト相を得る組成に共通して[110]の $1 / 3$ に散 漫散乱が現れている。この散乱はマルテンサイト相からの反 射ではなく，(110)の面間隔の約 3 倍周期を持った微細な静 的な中間生成物ができていると考えられる.

散漫散乱の測定は，以下に述べる $\mathrm{Au}-49.5$ at \% Cd の Bragg 反射の積分反射強度が変態温度に近づくにしたがって 約 $10 \%$ 程度減少することと関連していると考えられる ${ }^{(27)}$. 図 9 に200反射の積分反射強度の変化の様子を示してある. $\mathrm{Cu}$ の特性 X 線で測定すると積分反射強度が約 $10 \%$ 減少して いる.これは散漫散乱の原因となるものは体積にして $10 \%$ 程度であることを示唆している.この図ではさらに，Moで の測定では減少が見られない様子がわかる．これはMo と $\mathrm{Cu}$ の X 線の侵入深さの違いにより理解され, これらの微細 な中間生成物が表面近傍により多くできていることが推測さ れる(27).

$\mathrm{TiNi}(\mathrm{Fe})$ 合金に関しては，その基礎的興味から以前から このような実験が行われている. Shapiro ら ${ }^{(28)}$ は R 相の構 造が決定されていない時期に，( $h k 0)$ 面の二次元的な観察を 行い，1/3 に散漫散乱が現れることを報告している.さらに この散漫散乱は Brillouin zone の周期性を持っていないこと を報告している. $\mathrm{R}$ 相の結晶構造の決定の後にわれわれも同

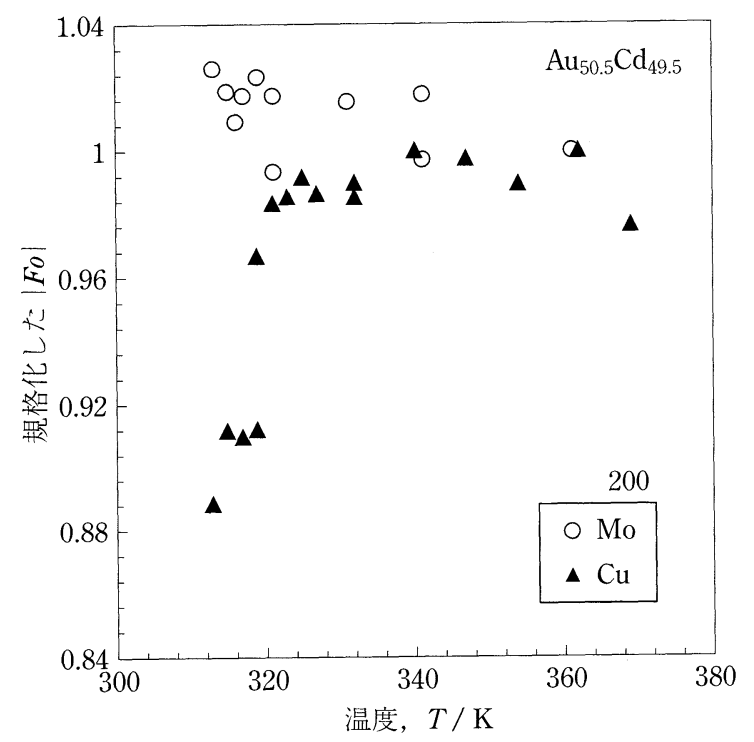

図 9 母相 200 Bragg 反射の積分反射強度の温度依存性 と波長依存性。
様な測定を行った ${ }^{(29)}$. その結果は $1 / 3$ からずれた位置に散 漫散乱が観察されている.この散漫散乱は変態点に近づくに したがって強度が強くなっていき, 変態すると急激に強くな る.これらの特徴は $\mathrm{AuCd}$ 合金にも見られ, 共通した特徵 といえる.

$\mathrm{TiNi}(\mathrm{Fe})$ 合金に関しては, 最近, エネルギーフィルター を用いた電子顕微鏡を使った詳細な実験も行われ(30), さら に実像の情報も得られている. それによると, マルテンサイ 卜変態に前駆した母相の状態で, 大きさ $10 \mathrm{~nm}$ 程度の微細 なドメイン状のものが観察されている.これらは一方向の (110)の面間隔の約 3 倍の周期を持ったものであると報告さ れている.

\section{6. マルテンサイト変態のメカニズム}

マルテンサイト変態のメカニズムに関しては, 母相とマル テンサイト相の結晶方位関係があり, 無拡散であるというこ とを考えると, 最初に述べたようなフォノンのソフト化とい う考え方が自然である. 実際, AuCd 合金や TiNi 合金で は, マルテンサイト相の結晶構造を作るようなフォノンのソ フト化も観察されているが，それですべてが解决するわけで はない. 過去の研究に戻って見てみても, マルテンサイト相 の結晶構造に対応したフォノンのソフト化の測定されていな いものも多くある(31). Au-47.5 at\% Cd の場合, 競合関係に あるうち $=1 / 2$ が選ばれ, B19 構造のマルテンサイト相に なる理由はフォノンだけからはない.フォォノは重要な引き 金にはなっているが，決定的な要因ではなさそうである. 最 近 $\mathrm{AuCd}$ 合金に対してバンド計算が行われ(32), フェルミ面 のネスティングが存在することが示され, 電子系の寄与の重 要性が示されている.

さらに Au-47.5 at\% Cd も Au-49.5 at\% Cd も弾性散乱を 観察した実験結果では，(110)の面間隔の 3 倍周期の中間生 成物が母相の状態の中に存在していることを示している. $\mathrm{TiNi}(\mathrm{Fe})$ でも同様なことが言える. 最近の電子顕微鏡観察 の結果 ${ }^{(30)}$ は, マルテンサイト変態に前駆して(110)の面間隔 の約 3 倍周期の微細な中間生成物ができ, マルテンサイト 相ができているようである. 中間状態を経てマルテンサイト 変態を起こすという考え方は， FePd 系には二つの正方晶が 混合した状態があるという報告があり (33), 電子顕微鏡によ り見られる tweed 組織(34) も一種の中間生成物と考えると, 共通したものかもしれない.

\section{7.さいごに}

エネルギー的な議論をすれば，母相とマルテンサイト相を 比べるとマルテンサイト相の方がエネルギーが小さくなるか ら変態が起こるのであるが，そのドライビングフォースは何 かと問われると, 今の段階で明確な解答はない.

フォノンのソフト化はなぜ起こるのか，中間生成物はなぜ できるのか，3 倍周期からのずれはなぜか，3 倍周期の中間 
生成物からマルテンサイトになるのにはどのようなメカニズ ムを必要とするのかなど, 今後の更なる研究が期待される. ここでは特に触れなかったが，これらはインキュベーション タイムの問題 ${ }^{(35)}$, マルテンサイト変態のカイネティック ス ${ }^{(36)}$ にもかかわり，今後解決すべき問題であろう.

最後に, この研究を遂行するに当たり研究室の学生はじ め，多くの方々にご協力いただいた。 また，大塚和宏教授 (現：産業技術総合研究所）には多くの議論や激励をいただい た.この研究の成果の一部は, 日米協力の中性子散乱実験, 科研費特定領域研究, 池谷科学技術振興財団, 材料科学研究 助成基金の助成によって得られたものである：この場をかり て感謝の意を表す。

\section{文献}

（1）清水謙一：まてりあ, 37(1998), 655 .

（2）清水謙一, R. Gotthardt：まてりあ, 39(2000), 257.

(3) P. Clapp: Mater. Sci. Eng., A127(1990), 189.

(4) P. Clapp: Phys. Status. Solidi., (b)57(1973), 561.

( 5 ) Y. Yamada, Y. Noda and M. Takimoto: Solid State Commun., 55 (1985), 1003.

(6) Y. Yamada: Proc. of International Conference on Martensitic Transformations, The Japan Institute of Metals, (1986), 89.

(7) R. J. Gooding and J. A. Krumhansl: Phys. Rev., 39(1989), 1535.

(8) F. Falk: Z. Physik., B51(1983), 177.

(9) G. B. Barsch and J. A. Krumhansl: Metall. Trans., 19A(1988), 761.

(10) G.-L. Zhao, T. C. Leung, B. N. Harmon, M. Keil, M. Müllner and W. Weber: Phys. Rev., B40(1989), 7999.

(11) G.-L. Zhao and B. N. Harmon: Phys. Rev., B45 (1991), 2818.

(12) T. Ohba, Y. Emura, S. Miyazaki and K. Otsuka: Mater. Trans., JIM, 31(1990), 12.

(13) T. Ohba, Y. Emura and K. Otsuka: Mater. Trans., JIM, 33(1992), 29.

(14) T. Hara, T. Ohba, E. Okunishi and K. Otsuka: Mater. Trans., JIM, 38(1997), 11.

(15) T. Tadaki and C. M. Wayman: Metallography, 15(1982), 233.
(16) T. Ohba, S. Raymond, S. M. Shapiro and K. Otsuka: Jpn. J. Appl. Phys., 37(1998), L64.

(17) T. Ohba, S. M. Shapiro, S. Aoki and K. Otsuka: Jpn. J. Appl. Phys., 33(1994), L1631.

(18) P. Moine, J. Allain and B. Renker: J. Phys. F: Metall. Phys., 14(1984), 2517.

(19) S. M. Shapiro, B. X. Yang, G. Shirane, Y. Noda and L. E. Tanner: Phys. Rev. Lett., 62 (1989), 1298.

(20) H. Tietze, M. Müllner and B. Renker: J. Phys. C: Solid State Phys., 17(1984), L529.

(21) X. Ren, K. Taniwaki, K. Otsuka and Y. Morii: J. Phys. Soc. Jpn., 70 (2001), Sippl. A, 280.

(22) G. R. Barsch, T. Ohba and D. M. Hatch: Mater. Sci. Eng. A273-275(1999), 161.

(23) Isotropy Subgroups of the 230 Crystallographic Space Groups, H. T. Stokes and D. M. Hatch: World Scientific Publishing Co. Pte. Ltd., (1988).

(24) T. Ohba: Proceedings of International Conference on SolidSolid Phase Transformations '99, Kyoto, invited paper, (1999), 815-822.

(25) T. Ohba, K. Sato and K. Otsuka: Mater. Sci. Forum, 327$328(2000), 377$.

(26) X. Ren, T. Ohba, S. Yamada, T. Ishii and K. Otsuka: Proceedings of The Third Pacific Rim International Conference on Advanced Materials and Processing, (1998), 1233.

(27) T. Ohba, L. Shi, T. Hara, H. Funaki and M. Sato: Mater. Sci. Eng., 312 (2001), 244.

(28) S. M. Shapiro, Y. Noda, Y. Fujii and Y. Yamada: Phys. Rev., B 30(1984), 4314.

(29) T. Ohba and Y. Miyata: Journal de Physique IV, in press.

(30) D. Shindo and Y. Murakami: Science and Technology of Advanced Materials 1(2000), 117-124.

(31) G. Guenin, S. Hautecler, R. P-ynn, P. F. Gobin and L. Delaey: Scr. Metall., 13(1979), 429-430.

(32) T. Kakeshita, T. Fukuda and T. Saburi: Science and Technology of Advanced Materials, 1(2000), 63.

(33) H. Seto, Y. Noda and Y. Yamada: J. Phys. Soc. Jpn., 59(1990), 965, 978.

(34) M. Sugiyama, R. Oshima and F. E. Fujita: Trans. JIM, 10 (1986), 719.

(35) H. Abe, M. Ishibashi, K. Ohshima, T. Suzuki, M. Wutting and K. Kakurai: Phys. Rev., 50(1994), 9020.

(36) T. Kakeshita, K. Kuroiwa, K. Shimizu, T. Ikeda, A. Yamagichi and M. Date: Mater. Trans., 34(1993), 423. 